\title{
Tapia's syndrome following cervical laminoplasty -A case report-
}

\author{
Kyung-Jee Lim¹, Man-Ho Kim , Mae-Hwa Kang ${ }^{1}$, Hyo Min Lee ${ }^{1}$, Eun Young Park ${ }^{1}$, Kwang-Jun Kwon², \\ Soo Kyung Lee ${ }^{1}$, Hyun $\mathrm{Choi}^{1}$, and Hyun Soo Moon ${ }^{1}$
}

${ }^{1}$ Department of Anesthesiology and Pain Medicine, College of Medicine, Hallym University, Anyang, ${ }^{2}$ Department of Dentistry, Gangneung-Wonju National University, Gangneung, Korea

Tapia's syndrome is the palsy of the 10th and 12th cranial nerves, resulting in ipsilateral paralysis of the vocal cord and tongue. It is a rare complication which is related to the anesthetic airway management and positioning of the patient's head during the surgery. We describe a patient with a postoperative unilateral Tapia's syndrome, after general anesthesia, with uncomplicated endotracheal intubation. The patient's symptoms improved gradually for three months. (Korean J Anesthesiol 2013; 64: 172-174)

Key Words: Airway management, Tapia's syndrome.

Tapia's syndrome, first described in 1904 by Tapia AG, is the palsy of the recurrent laryngeal and hypoglossal nerves, affecting the ipsilateral vocal cord and tongue [1]. According to the degree of involvement of the nerves, different symptoms, such as hoarseness, dysphagia, dysarthria and dyspnea, can be present. Although rare, it can complicate general anesthesia with endotracheal intubation. We report a case of postoperative unilateral paralysis of the recurrent laryngeal branch of the vagus nerve and hypoglossal nerve after cervical laminoplasty.

\section{Case Report}

A 64-year-old man (height $169 \mathrm{~cm}$, weight $70 \mathrm{~kg}$ ) was presented for laminoplasty C3-7 due to incomplete cervical spinal cord injury. He started taking antihypertensive medication daily a year ago. Except that, the patient was in good health until he fell from a three-meter-high cliff. Four weeks ago, he had an emergency operation, anterior cervical discectomy and fusion (ACDF) C3-7, under general anesthesia, and no specific events happened during the perioperative period. Anesthesia was induced using a propofol and remifentanil, and the paralysis was facilitated with rocuronium. Endotracheal intubation was achieved using a light-wand and a reinforced endotracheal tube of the inner-diameter $7.5 \mathrm{~mm}$ was successfully placed. Anesthesia was maintained with sevoflurane and 50\% oxygen in the air. A three-pin head holder was affixed to the patient's head. After the patient was turned prone, the surgeons slightly moved his neck to find an appropriate position and fixed the holder with the head in a neutral position. The total anesthetic and operation time was $405 \mathrm{~min}$ and $310 \mathrm{~min}$, respectively,

Received: April 2, 2012. Revised: May 18, 2012. Accepted: May 21, 2012.

Corresponding author: Soo Kyung Lee, M.D., Department of Anesthesiology and Pain Medicine, Hallym University Sacred Heart Hospital, 896, Pyeongchon-dong, Dongan-gu, Anyang 431-071, Korea. Tel: 82-31-380-3945, Fax: 82-31-385-3244, E-mail: agnetask@yahoo.co.kr (c) This is an open-access article distributed under the terms of the Creative Commons Attribution Non-Commercial License (http:// creativecommons.org/licenses/by-nc/3.0/), which permits unrestricted non-commercial use, distribution, and reproduction in any medium, provided the original work is properly cited. 
and the blood loss was estimated to be $700 \mathrm{ml}$. The patient was extubated after a full recovery of respiration and consciousness, and was transferred to the general ward.

On the first postoperative day, the patient began to complain of dysphagia and recurrent aspiration, and the symptoms have persisted for two days. A rigid fiberoptic laryngoscope showed the deviation of the tongue to the left on protrusion, the absent movement of the left vocal cord and the pooling of saliva in the left pyriform sinus. Neurologic examination revealed the palsy of the left hypoglossal and recurrent laryngeal nerves. Video fluoroscopic swallowing study (VFSS) showed the impairment of pharyngeal contraction on swallowing and left side deviation and atrophy of the tongue. There was no uvula deviation or abnormality of the soft palate elevation. On neurologic examination, there were palsy of the left hypoglossal and recurrent laryngeal nerve, and the remainder was normal. On a magnetic resonance imaging of the brain and neck, there was no evidence to suspect central neurologic or vascular involvement. These findings suggested a peripheral type of Tapia's syndrome. Conservative management included intravenous corticosteroid, electrical stimulation therapy aimed at a restoration of swallowing ability and the nasogastric tube feeding to reduce the risk of aspiration. VFSS-guided balloon dilation of the esophagus was also performed. Seven weeks after the operation, the patient's symptoms began to improve and he started a soft diet. He gradually recovered thereafter, and was discharged three months later.

\section{Discussion}

Tapia's syndrome is the palsy of the recurrent laryngeal and hypoglossal nerves, which affects the ipsilateral vocal cord and tongue [1]. Some cases of anesthesia-related Tapia's syndrome have been reported. Most of the patients had a history of orotracheal intubation [2-9]. Johnson and Moore [10] reported this syndrome after an interscalene brachial plexus block. There was a case caused by the placement of a nasogastric tube, and was worsened by the administration of heparin during cardiac surgery [11]. The most frequently involved operations were septoplasty and septorhinoplasty $[4,5,9,10]$. However, Tapia's syndromes following a shoulder surgery [2], a repair of a fractured mandible [12] and thoracotomies including coronary artery bypass surgery $[3,6,7,11]$ were also described. Although most of the cases are unilateral, bilateral Tapia's syndromes have been reported. In these cases, the symptoms that mimicked laryngospasm were present after extubation [4] and another experienced a postoperative airway obstruction following a failed extubation [6]. Most patients with this syndrome have made a complete recovery within several months. In a case report, however, left hypoglossal nerve palsy still remained even after 16 months [12]. The treatment is usually supportive, with or without a short course of systemic corticosteroid, depending on the extent of the nerve damage [8]. In our patient, Tapia's syndrome was developed following a laminoplasty, and the progressive recovery of the patient's symptoms with steroid and conservative treatment suggests a neuropraxia, which is typically caused by a compression injury.

The possible mechanisms of Tapia's syndrome, associated with general anesthesia, include a direct compression of the recurrent laryngeal and hypoglossal nerves by an endotracheal tube [3-5], a prolonged stretch of these nerves following an excessive flexion of the head $[2,3,5]$, and a trauma to the carotid artery involving the ascending pharyngeal artery [10]. Anatomically, the hypoglossal nerve rests on the most lateral prominence of the anterior surface of the transverse process of the first cervical vertebra and crosses the vagus nerve [13]. There is a close vicinity of the hypoglossal and vagus nerves to the lateral wall of the lower part of the oropharynx, and the upper part of the hypopharynx [9]. This relationship between the vagus and hypoglossal nerves may explain the possible mechanism of a simultaneous injury.

There are several possible causes of Tapia's syndrome in our patient. One cause of Tapia's syndrome in this patient is likely to be the compression of both nerves by the endotracheal tube, and its cuff on a localized area. There is a possibility of an inadvertent movement of the tube, leading to the compression of the pharynageal wall during a position change. The head of our patient has not been markedly flexed laterally during the surgery. However, our patient's head was repeatedly repositioned by the surgeons to obtain a suitable surgical field, and stretching injury of the nerves by an excessive anterior flexion of the head may be another cause. The surgeon denied possibility of any surgical injury. However, Fountas et al. [14] reported that postoperative dysphagia, hematoma, and recurrent laryngeal nerve palsy were the most common complications following ACDF. Therefore, surgery-related effect cannot be excluded completely.

Although we did not check the cuff pressure of the endotracheal tube, proper cuff pressure is an important factor, which affects the intubation-related postoperative complication, such as postoperative sore throat, hoarseness, and dysphagia. Maintaining an endotracheal tube cuff pressure less than 20 $\mathrm{mm} \mathrm{Hg}$ throughout the procedure is recommended to reduce patient's discomfort following an anterior cervical spine surgery [15].

In conclusion, although Tapia's syndrome is rare, both anesthesiologists and surgeons need to be aware that this complication can accompany any kind of surgery. It is not easy to keep the patient's head in a proper alignment when the body is covered with a sterile drape, and thereby, direct access is limited. Special 
attention should be paid to correct the positioning of the head and neck during every procedure, and also to the careful airway management, such as a confirmation of the position and fixation of the endotracheal tube, and a proper cuff inflation.

\section{References}

1. Schoenberg BS, Massey EW. Tapia's syndrome. The erratic evolution of an eponym. Arch Neurol 1979; 36: 257-60.

2. Boisseau N, Rabarijaona H, Grimaud D, Raucoules-Aime M. Tapia's syndrome following shoulder surgery. Br J Anaesth 2002; 88: 86970.

3. Gelmers HJ. Tapia's syndrome after thoracotomy. Arch Otolaryngol 1983; 109: 622-3.

4. Cinar SO, Seven H, Cinar U, Turgut S. Isolated bilateral paralysis of the hypoglossal and recurrent laryngeal nerves (Bilateral Tapia's syndrome) after transoral intubation for general anesthesia. Acta Anaesthesiol Scand 2005; 49: 98-9.

5. Tesei F, Poveda LM, Strali W, Tosi L, Magnani G, Farneti G. Unilateral laryngeal and hypoglossal paralysis (Tapia's syndrome) following rhinoplasty in general anaesthesia: case report and review of the literature. Acta Otorhinolaryngol Ital 2006; 26: 219-21.

6. Sotiriou K, Balanika M, Anagnostopoulou S, Gomatos C, Karakitsos D, Saranteas T. Postoperative airway obstruction due to Tapia's syndrome after coronary bypass grafting surgery. Eur J Anaesthesiol 2007; 24: 378-9.
7. Nalladaru Z, Wessels A, DuPreez L. Tapia's syndrome - a rare complication following cardiac surgery. Interact Cardiovasc Thorac Surg 2012; 14: 131-2.

8. Boga I, Aktas S. Treatment, classification, and review of Tapia's syndrome. J Craniofac Surg 2010; 21: 278-80.

9. Lykoudis EG, Seretis K. Tapia's syndrome: an unexpected but real complication of rhinoplasty: case report and literature review. Aesthetic Plast Surg 2012; 36: 557-9.

10. Johnson TM, Moore HJ. Cranial nerve X and XII paralysis (Tapia's syndrome) after an interscalene brachial plexus block for a left shoulder Mumford procedure. Anesthesiology 1999; 90: 311-2.

11. Rotondo F, De Paulis S, Modoni A, Schiavello R. Peripheral Tapia's syndrome after cardiac surgery. Eur J Anaesthesiol 2010; 27: 575-6.

12. Kashyap SA, Patterson AR, Loukota RA, Kelly G. Tapia's syndrome after repair of a fractured mandible. Br J Oral Maxillofac Surg 2010; 48: 53-4.

13. Rubio-Nazabal E, Marey-Lopez J, Lopez-Facal S, Alvarez-Perez P, Martinez-Figueroa A, Rey del Corral P. Isolated bilateral paralysis of the hypoglossal nerve after transoral intubation for general anesthesia. Anesthesiology 2002; 96: 245-7.

14. Fountas KN, Kapsalaki EZ, Nikolakakos LG, Smisson HF, Johnston KW, Grigorian AA, et al. Anterior cervical discectomy and fusion associated complications. Spine (Phila Pa 1976) 2007; 32: 2310-7.

15. Ratnaraj J, Todorov A, McHugh T, Cheng MA, Lauryssen C. Effects of decreasing endotracheal tube cuff pressures during neck retraction for anterior cervical spine surgery. J Neurosurg 2002; 97(2 Suppl): 176-9. 